\title{
Failure Mode Identification by Pattern Recognition with Acoustic Emission Technique - A Case Study on UDL carbon-Epoxy Specimens
}

\author{
M. R. M. Babu ${ }^{1}$,T.V.K. Bhanuprakash ${ }^{2}$ \\ ${ }^{1}$ Advanced Systems Laboratory, Kanchanbagh, Hyderabad-500058, AP, India \\ ${ }^{2}$ Department of Marine Engineering, AU College of Engineering, Visakhapatnam -530 003, AP, India
}

\begin{abstract}
Acoustic emissions (AE) generated by a structure under stressed condition provides a passive means to characterise defect initiation and defect growth in the structure.Composite structures are best evaluated by such new techniques. The amount of heterogeneity and presence of various failure mechanisms increase the complexity of Acoustic Emission evaluation. AE data has been generated by conducting tensile tests on carbon epoxy Uni-Directional Longitudinal (UDL) specimens. Failure mechanisms like matrix cracking and fiber breakage have been characterized by comparing and correlating significant AE parameters acquired from various specimens by employing Visual Pattern Recognition Technique.The amplitude distribution, cumulative amplitude distribution and cumulative signal strength parameters have been studied in correlation with applied load. The cumulative amplitude plot is bi-linear indicating the presence of two distinct failure mechanisms. The change of slope (break in linearity) occurs at $85 \mathrm{~dB}$ which is a vivid indication of fibre breakage initiation. There are a large number of Acoustic Emission Hits associated with energies less than 100 units which represent the matrix-cracking spectrum. The cumulative signal strength plot indicates the onset of damage of the specimen at about 70\%-80\% of the load. The onset of Historic Index (Rate of variation of Cumulative Signal Strength w.r.t Load) exceeding 6 also indicates damage initiation in the specimen.
\end{abstract}

Keywords:Acoustic Emission, Visual Pattern Recognition, Carbon-Epoxy Composite

\section{Introduction}

The carbon epoxy composite materials are finding an increased usage in the aerospace industry as structural materialdue to their superior specific strength and specific stiffness. One such application is filament wound carbon epoxy rocket motor casing for solid propulsion systems. Acoustic emission testing is a rapidly developing nondestructive tool which can effectively be used for real time structural health monitoring of composite pressure vessels under stress during hydro proof pressure testing [1]. Both microscopic and macroscopic defects in the vessel which would grow under stressed condition can be evaluated and it enables to evaluate the location as well as classification of flaw growth within the structure. The structural health monitoring of T700 carbon epoxy filament wound Composite Rocket Motor Casing (CRMC) with acoustic emission testing is under study by the authors.

The AE technology is based on acquisition and analysis of sound waves produced by the growing flaws in a material under stress with the help of piezoelectric sensors. The sensors convert the acoustic waves hitting the face of the piezoelectric element in to electrical signals which resemble sinusoids with short rise time and exponential decayand has peak amplitude of the order of a few milli volts. The signal is made to pass through an amplifier so as to increase its amplitude to a usable voltage. Generally $40 \mathrm{~dB}$ a setting (100X amplification) is used. An AE waveform of a signal is normally displayed on a voltage vs. timeplot as shown in Fig.1.Thevarious parameters of the AE signal represent a specific failure mechanism and are summarized in Table $\mathbf{1 .}$

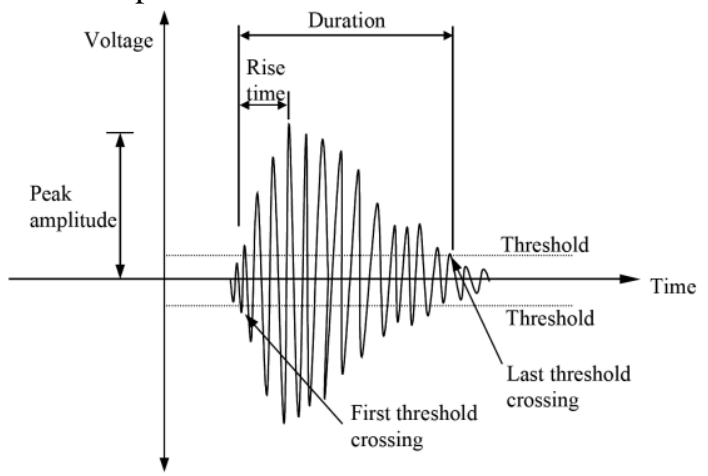

Fig.1 Acoustic Emission Waveform Parameters 


\section{Table 1 AE Waveform Parameters}

\begin{tabular}{|l|l|}
\hline Hit & The detection and measurement of an AE signal. (Onset of threshold crossing) \\
\hline Duration & Time from the first to the last threshold crossing in microseconds. \\
\hline Threshold & It is set for eliminating electronic background noise which normally has low amplitude. \\
\hline Count & The number of times the AE signal exceeds a pre-set threshold \\
\hline Peak Amplitude & The highest point of the signal waveform \\
\hline Rise time & Time from first threshold crossing to the occurrence of peak amplitude in microseconds \\
\hline Signal strength & The area under the envelope of the analog voltage signal \\
\hline Energy & It is the area represented by the rectified AE signal waveform \\
\hline
\end{tabular}

Under internal pressure the CRMC experiences principally hoop load which initiates different types of failure mechanisms. There aremany research papers describing the various types of damage mechanisms in polymer composite structures [2,3]. The predominant failure modes are matrix cracking, fiber breakage and delaminations [4]. These are listed inTable 2.

\section{Table 2 Polymer Composite Materials - Predominant Failure Modes}

\begin{tabular}{|l|l|l|}
\hline $\begin{array}{l}\text { Matrix } \\
\text { Cracking }\end{array}$ & $\begin{array}{l}\text { Matrix or resin crackingoccurs when the matrix strain reaches the } \\
\text { ultimate strain }\end{array}$ \\
\hline $\begin{array}{l}\text { Fiber } \\
\text { Breakage }\end{array}$ & $\begin{array}{l}\text { Fiber breakage fracture occurs when a polymer compositecomponent } \\
\text { is under tensile stress and the fiber material reaches the ultimate stress }\end{array}$ \\
\hline Delamination & $\begin{array}{l}\text { Delamination is the separation between two layers. It is a } \\
\text { combinationof fiber-matrix debonding and matrix cracking [3]. }\end{array}$ \\
\hline
\end{tabular}

The acoustic emission data interpretation for CRMC under internal pressure is complex due to the simultaneous occurrence of different failure mechanisms. Generation of extensive AE database on test coupon level and identifying AE signature of different failure mechanisms is essential for taking up AE testing of CRMC. In the current study, Visual Pattern Recognition Technique has been employed to identify and segregate various failure mechanisms from various AE correlation plots. For establishing the efficacy of the technique a case study has been carried out with static tensile testing of specimens made from unidirectional laminate of carbon epoxy in fiber direction which is the simplest way of testing fiber breakage as principal mode of failure.

\subsection{Test specimen preparation}

\section{Experimental setup and test procedures}

Unidirectional laminate with T-700 carbon fiber impregnated in high temperature curing epoxy resinhas been prepared by filament winding process in hoop direction on a diamond shaped mandrel to simulate the CRMC manufacturing process. The tensile specimens of $200 \times 15 \times 2 \mathrm{~mm}$ sizes are cut from the laminate in fiber directionper the ASTM standard.[5](Shown in Fig.2.)

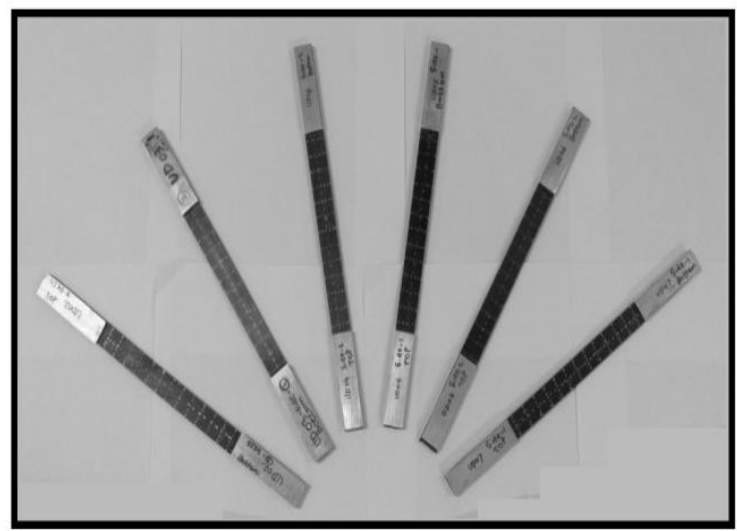

Fig. 2Uni-Directional Longitudinal (UDL) Tensile test specimens

\subsection{Experimental Set up}

$\mathrm{M} / \mathrm{s}$. Instron make, $100 \mathrm{KN}$ universal testing machine with closed loop screw driven system is used for carrying out tensile testing and load versus displacement andstrain curves are obtained independently.M/s. PAC,USA, make Acoustic Emission system with AEwinsoftware was used for on-line acoustic emission 
monitoring. M/s.PAC make, R15D type differential typepiezoelectric transducers are usedwith an external preamplifier to pick up the acoustic emission signals from the specimens. These sensors have an operating bandwidth of $100 \mathrm{KHz}$ to $500 \mathrm{kHz}$ with a peak resonant frequency of around $150 \mathrm{kHz}$.

The following AE settings were used for the test

- Threshold: 40dB

- Peak definition time (PDT): $20 \mu \mathrm{sec}$

- Hit definition time (HDT): $50 \mu \mathrm{sec}$

- Hit lock-out time (HLT): $300 \mu \mathrm{sec}$

The AE test up is shown in Fig.3. The specimens are subjected to static tensile loading gradually up to failure and parallelly the load, strain,displacement and acoustic emissions were recorded.

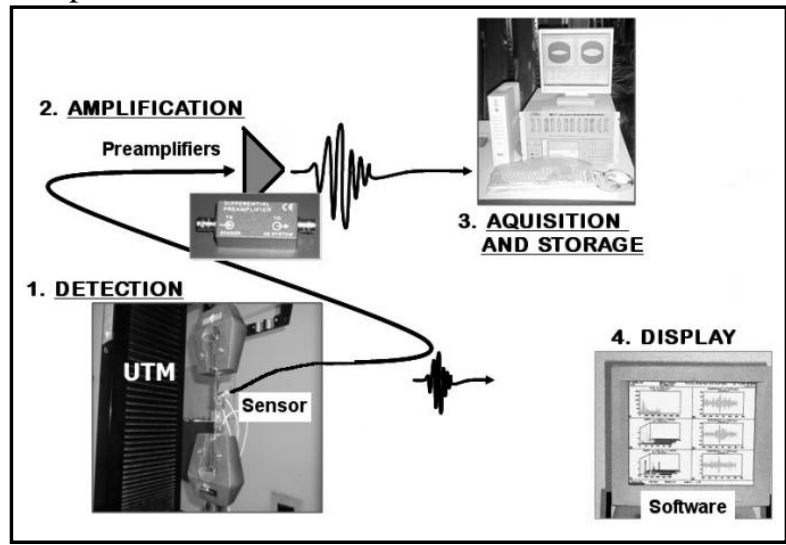

Fig.3. AE Test Setup

\subsection{Testresults}

\section{Results and Discussions}

Totally six number of specimens were tested and the test data is summarized in Table.3. The strain and displacement curves are found in linear trend with respect to load.

Table 3: AE Test data with respect load

\begin{tabular}{|l|l|l|l|l|l|l|l|}
\hline Parameter & $\begin{array}{l}\text { Failure } \\
\text { Load (KN) }\end{array}$ & $\begin{array}{l}\text { Total no. } \\
\text { of hits }\end{array}$ & $\begin{array}{l}\text { Total } \\
\text { energy }\end{array}$ & $\begin{array}{l}\text { Total signal } \\
\text { strength }\end{array}$ & $\begin{array}{l}\text { Amplitude } \\
\text { range db }\end{array}$ & $\begin{array}{l}\text { Duration } \\
\text { range } \mu \mathrm{s}\end{array}$ & $\begin{array}{l}\text { Rise } \\
\text { time } \\
\text { range } \\
\mu \mathrm{s}\end{array}$ \\
\hline$\# 01$ & 59.6 & 2610 & 174267 & $1.15 \mathrm{E}+09$ & $48-100$ & $38-46361$ & $1-243$ \\
\hline$\# 02$ & 48 & 1207 & 51415 & $3.24 \mathrm{E}+09$ & $49-100$ & $161-266010$ & $1-229$ \\
\hline$\# 03$ & 42 & 1850 & 26340 & $1.69 \mathrm{E}+09$ & $55-100$ & $119-292590$ & $1-210$ \\
\hline$\# 04$ & 54 & 8738 & 430650 & $2.71 \mathrm{E}+09$ & $46-100$ & $39-40347$ & $1-196$ \\
\hline$\# 05$ & 54 & 8922 & 292270 & $1.85 \mathrm{E}+09$ & $47-100$ & $32-122950$ & $1-174$ \\
\hline$\# 06$ & 69.5 & 6687 & 220413 & $1.40 \mathrm{E}+09$ & $47-99$ & $28-32810$ & $1-141$ \\
\hline
\end{tabular}

The principal failure mode in UDL samples is by fiber breakage which happens towards the end of the test. However weak fiber failure may be observed at the early stage of loading. As stated earlier the sample under tensile load may exhibit three types of failure mechanisms and they occur in sequence as follows [6,7].

i) Matrix micro cracking is excessive during the initial phase of loading and is present during the entire loading cycle.

ii) Excessive matrix cracking leads to separation of bunch of fibres called delamination. Such activities drastically reduce the specimens load carrying capabilities[8]

iii) The fiber breakages cause ultimate failure of the specimen

The ultimate failure load depends on the percentage dominance of de-lamination and fiber breakage. Accordingly the failure load is varying from $42 \mathrm{KN}$ to $69.5 \mathrm{KN}$ in the various specimens. The specimen No \# 06 which has shown the highest damage and fiber breakage recorded highest failure load and the specimen \# 3 which had shown the least damage and less fiber breakage recorded the least failure load.The failure mode of two typical specimens is shown in Fig.4. 


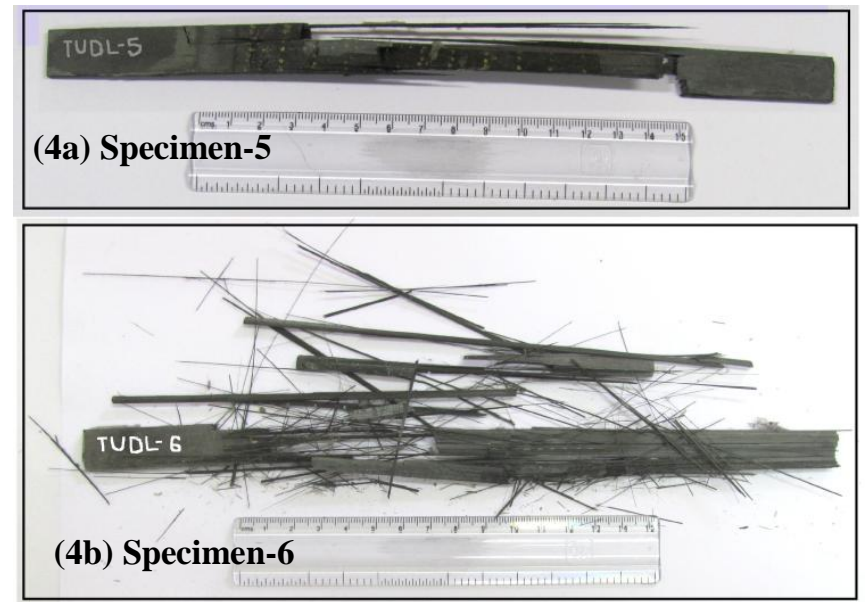

Fig.4 Failure modes in tested specimens

\subsection{Visual pattern recognition with $\mathrm{AE}$ correlation plots}

The $\mathrm{AE}$ data acquired during the tests has been post processed with Matlab software and $\mathrm{AE}$ correlation plots were generated for visual pattern recognition to identify the failure mechanisms. The load is normalized for ease of comparison of the data for different specimens. Each type of correlation plot and corresponding observations are presented in the following sections.

\section{i. Amplitude Vs. normalised loadplots}

This is a preliminary plot in acoustic emission testing which depicts the amplitude of $\mathrm{AE}$ hits in $\mathrm{dB}$ with respect to the load. Fig. 5showsthese plots for two select specimens. In all the specimens theonset of acousticemissions is observedat early stage of loading i.e. around 5\% of the breaking load. The AE activity exhibits marginal intensity in the initial phase of loading. At around $60 \%$ to $70 \%$ of the breaking load there is a steep increase in the AE intensity whichcontinued up to failure which indicates the onset of damage.
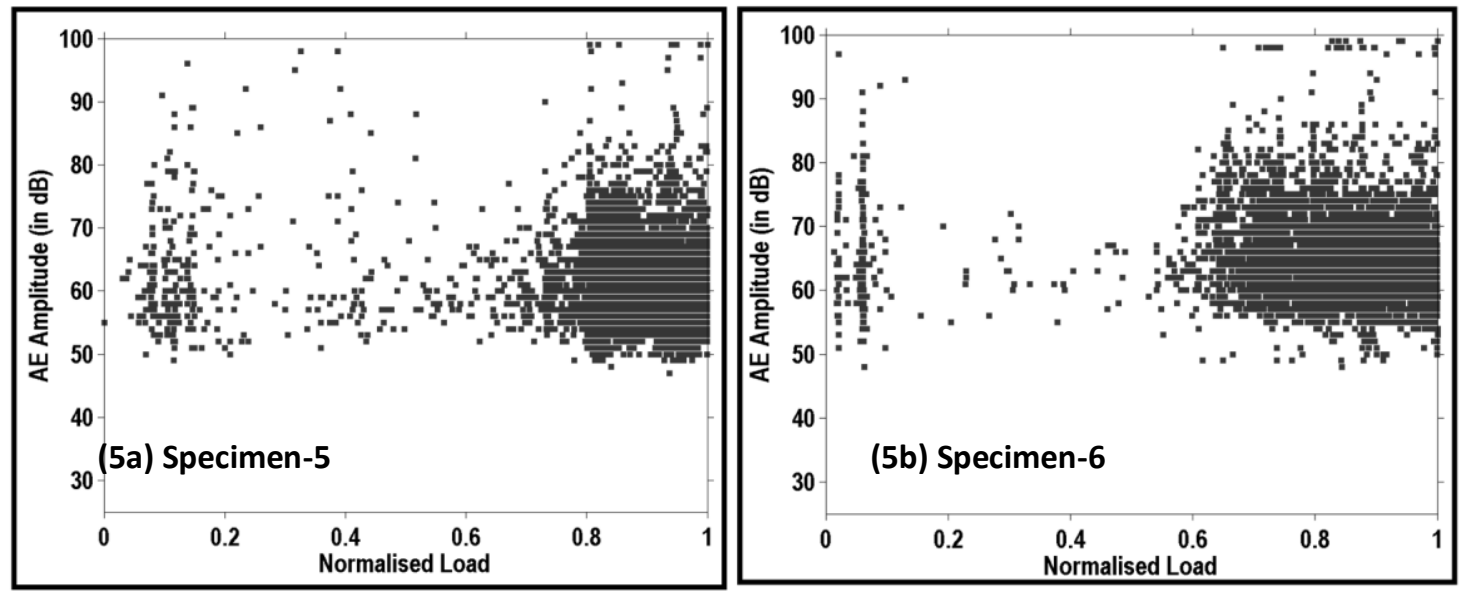

Fig.5.Amplitude-load plots

\section{ii. Amplitude distribution at various percentage of loads}

The amplitude distribution depicts the amplitude of $\mathrm{AE}$ hits with respect to number of hits. The plots have been sketched at 20\%, 40\%, 60\%, 80\%, 90\% and 100\% of failure loads. Fig.6 shows the amplitude distribution plots for the select two specimens. The distribution is dominant between $55 \mathrm{~dB}$ to $85 \mathrm{~dB}$ for all the specimens. This indicates that majority of the AE hits are attributed by such amplitude ranges. The peak of the distribution lies between $58 \mathrm{~dB}$ to $75 \mathrm{~dB}$. There is significant amount of acoustic emissions at after $80 \%$ of the load for all the specimens which indicate the safe load limit for the specimens. The peak amplitude distribution is almost consistent for all percentage of loads. This indicates that the matrix crackingis dominant in the entire loading cycle. The amplitude distribution plots for all the specimens are skewed towards lower amplitude side.The skewing of the amplitude distribution plot is anindication of relative matrix strength ofspecimens[6]. It can be seen that for specimen 5 , the peak occurred at $58 \mathrm{~dB}$ and for Specimen 6 , the peak has occurred at $63 \mathrm{~dB}$. Hence the higher breaking load of Specimen 2 is substantiated. 


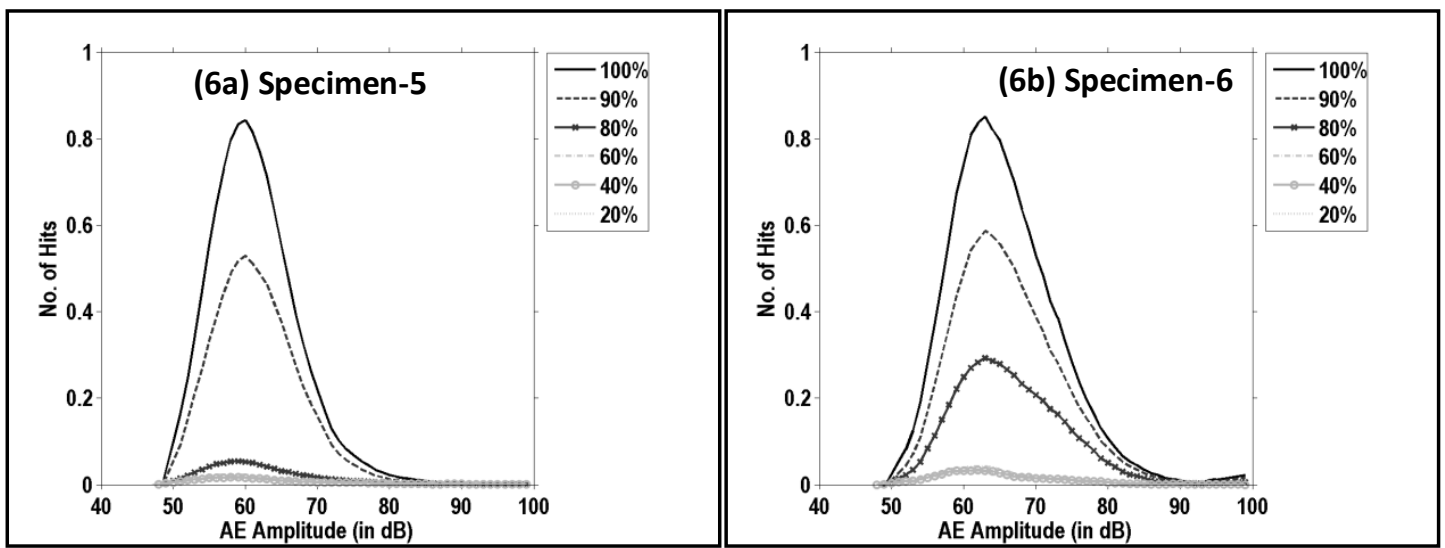

Fig.6 Progressive amplitude distribution plots

\section{iii. Cumulative amplitude distribution plotsat various percentage of loads}

Some researchers have reported that the slope of the cumulative amplitude distribution curve indicates the dominant failure mechanism and the presence of two dominant failure modes give rise to bilinear nature to the cumulative amplitude distribution plot [9]. The cumulative amplitude distribution plots have been made at various percentages of the failure loads for all the specimens. Fig.7 shows the cumulative amplitude distribution for the two select specimens.

The curves of all the specimens exhibit a linear trend up to around $80 \%$ of the breaking load beyond which bi-linearity ( 2 distinct slopes) is noticed. The point of inflection appears at around $85 \mathrm{~dB}$ to $90 \mathrm{~dB}$ across various specimens. The number of slopes in the plot indicates number of failure modes that the sample experienced. Hence it can be concluded that, matrix cracking has been dominant until $80 \%$ of the load and beyond this fiber breakage initiates with AE hits of amplitudes higher than 85 to $90 \mathrm{~dB}$. The slope of the cumulative amplitude plot representing matrix cracking is in the range of 0.9 to 1.3 and that of fiber breakage is in the range of 0.45 to 0.7 .

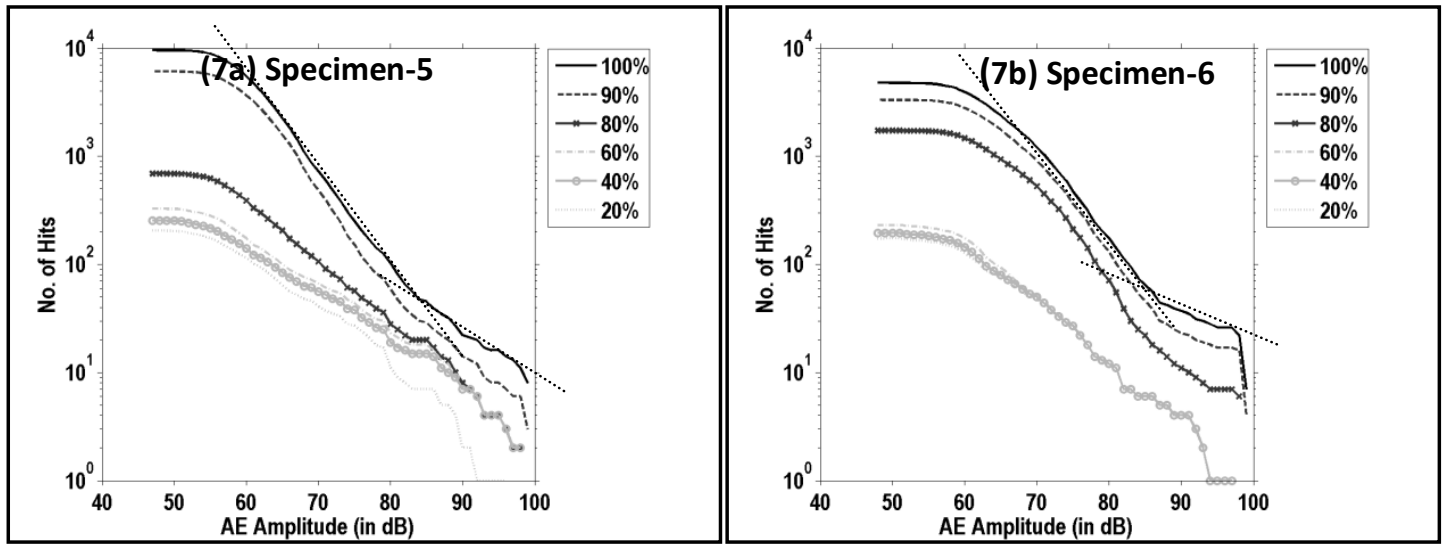

Fig.7 Progressive cumulative amplitude distribution plots

iv. Energy Vs. load plots and amplitudes of different energy groups Vs. load plots

The magnitude of energy/ signal strengthof an $\mathrm{AE}$ hit is indicative of its relative damage potential. Hence higher failure mode like fiber failure is associated with high energy/ signal strength hits. Fig.8shows the acoustic energy versus normalized load plot for a select specimen. In general for all the specimens energy of the $\mathrm{AE}$ hits is within 1000 units in the initial phase up to 70 to $80 \%$ of the load after which it has raised up to 15000 to 50000 units. This indicates that maximum amount of energy is contributed by fiber breakage which is the dominant failure mechanism after 70 to $80 \%$ of load.

The plots have been made for the AE hits with amplitude Vs. load with two groups of energy. First group contains AE hits up to 100 units of energy and second group contains with energies above 100 units. The plot for a select specimen is shown in Fig. 9. These plots show that the AE hits with less than 100 units of energy are more dominant in number and they are within $85 \mathrm{~dB}$ amplitude. Hence lower failure mechanisms like matrix cracking are characterised by amplitudes less than $85 \mathrm{~dB}$. Hits with higher energy (energy $>100$ ) are spreading from $65 \mathrm{~dB}$ and above. The high energy hits above $85 \mathrm{~dB}$ is dominated by fibre breakage mechanism. Moderate energy hits from $65 \mathrm{~dB}$ and above may represent matrix at macro level or delamination. 


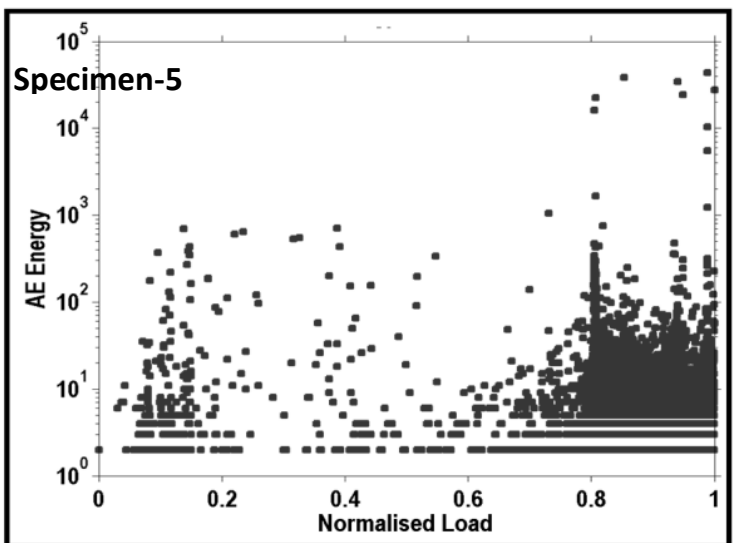

Fig.8Energy Vs. load plot

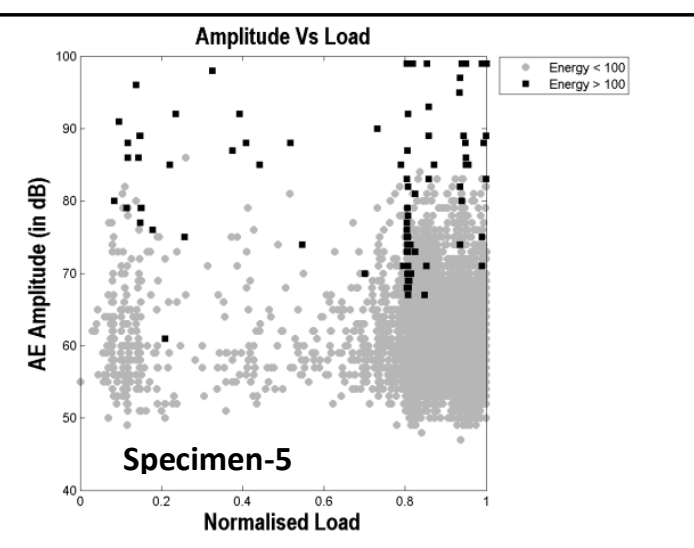

Fig.9. Hits of different energy plot

\section{v. Normalised cumulative signalstrengthand Historic index Vs. loadplots}

The cumulative signal strength with respect to load plot will be very useful in identifying the initiation of high damage potential mechanisms in terms of steep change in slope of the plot. The damage severity can also be identified by historic index which represents rate of change of signal strength per unit load. Fig.10shows normalized cumulative signal strength as well as Historic index with respect to load for the select specimens. These cumulative signal strength plots for all the specimens confirm the onset of fiber failure mechanism at about $70 \%$ to $80 \%$ of the failure load with steep rise in signal strength. At the same location the historic index is in excess of 6 for all the specimens.

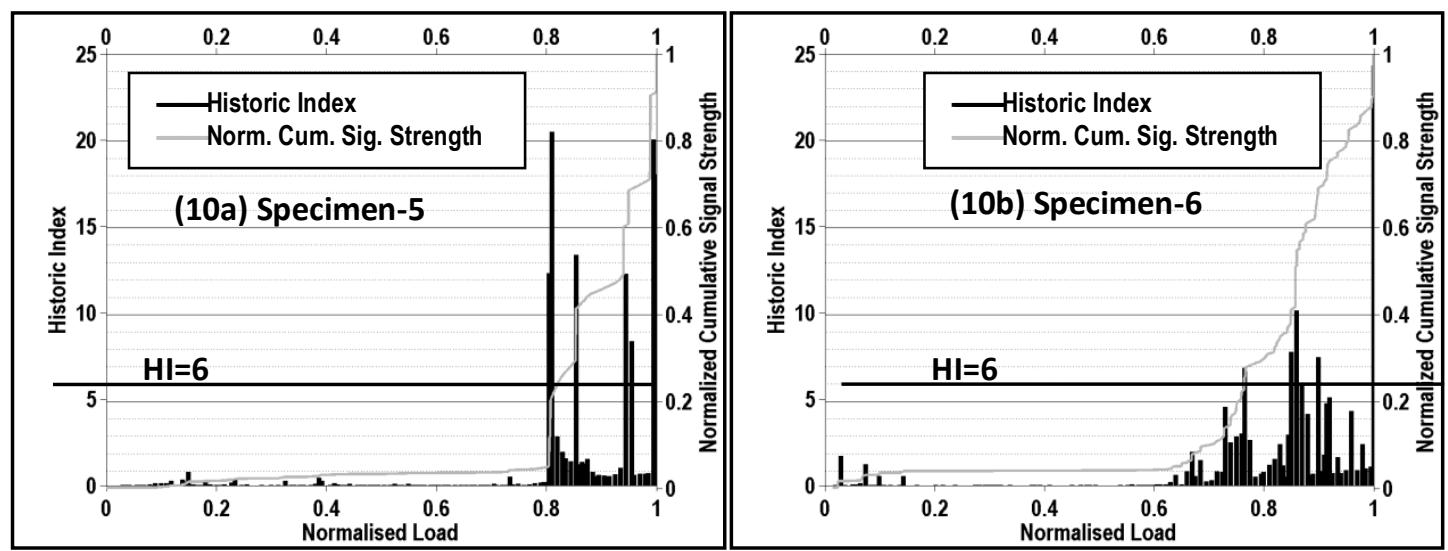

Fig.10 Historic index Vs. load plots

\section{vi. Duration Vs. amplitude plots}

These plots are generally used as key to evaluate the quality of the AE data. The Duration Vs amplitude plots for select specimens are shown in Fig. 11. It can be seen that very short duration, high amplitude hits that largely represent Electro-Magnetic Interference (EMI) are absent. Similarly, low amplitude, long duration hits that may occur due to grip slippage are also absent. Therefore the test instrumentation used for the experimental program has resulted in the recording of clean AE data. 

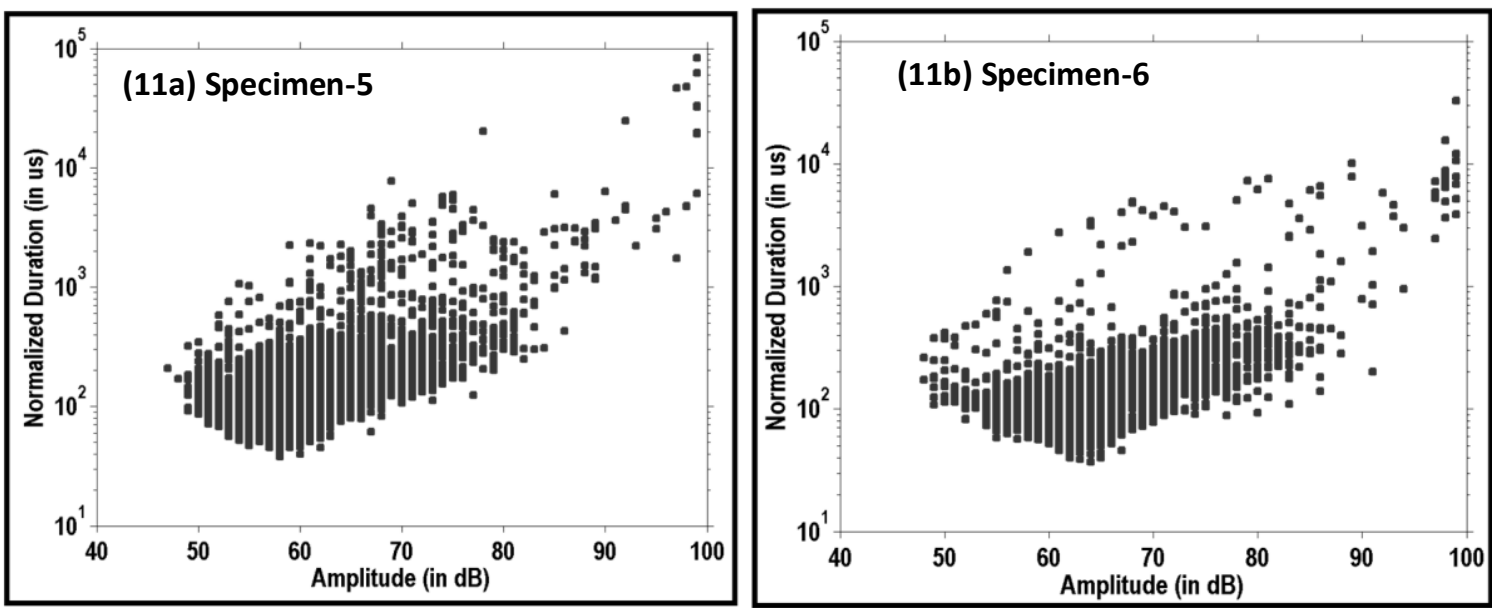

Fig.11. Duration versus no.of hits plots

\section{vii. Duration Vs. normalised loadplots and duration distribution plots}

The duration of an acoustic signal is a characteristic feature for the given failure mechanism and for a given failure mechanism its magnitude is proportional to the energy content of the signal. The Duration Vs. normalised load plot for a select specimen is shown in Fig.12. These plots indicate that long duration hits with high energy content occur in the higher phase of loading. These are contributed by fiber breakage mechanism. The AE hits contributed by matrix cracking are of short durations.

The duration distribution plots (Fig.13 shows duration distribution plot for a select specimen) confirm that the majority of the $\mathrm{AE}$ hits are contributed by matrix cracking mechanism that are of shorter duration less than $10^{4}$ micro seconds. The long duration hits are contributed by fiber breakage and are less in number.
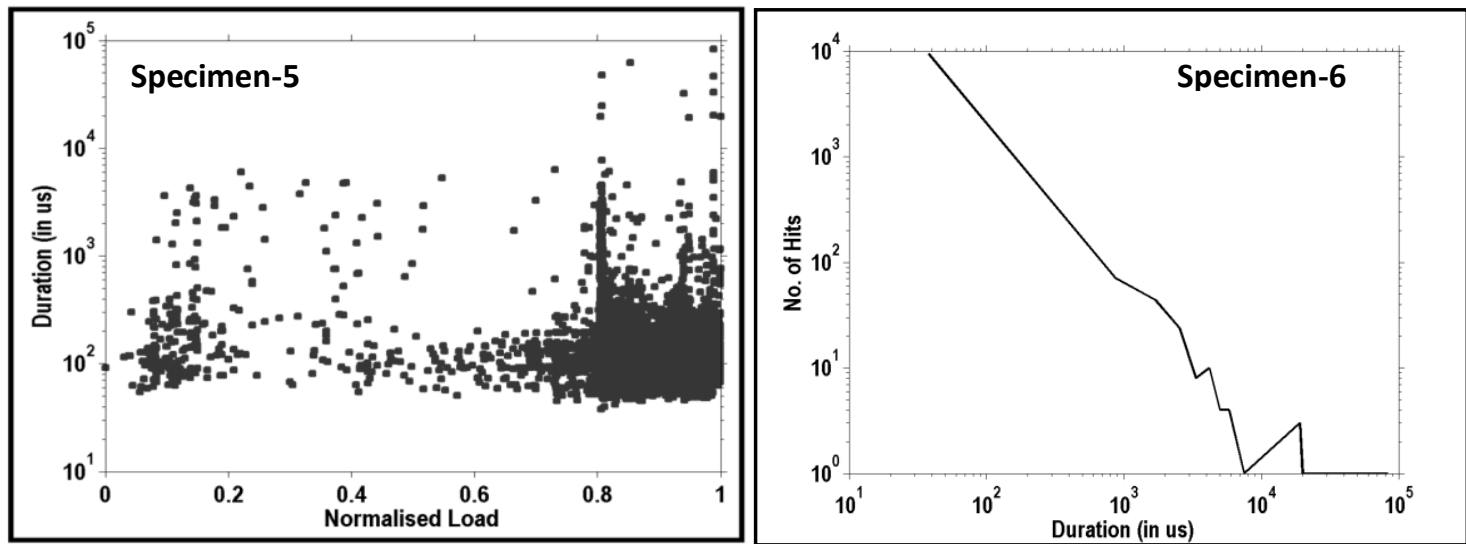

Fig.12.Duration Vs.Load plotFig.13.Duration distribution plot

\section{Conclusions}

AE data has been generated by conducting static tensile tests on Unidirectional longitudinal (UDL) specimens of T700 carbon epoxy composite material as a case study. Visual Pattern Recognition Technique has been employed to identify and segregate failure mechanisms. The following conclusions were drawn.

i) The matrix cracking represented by $\mathrm{AE}$ hits of up to 85 to $90 \mathrm{~dB}$ amplitude is dominant in entire loading cycle.The micro matrix cracking is represented by AE hits with energy less than 100 unitsand short duration.

ii) The peak of the amplitude distribution is around 60 to $75 \mathrm{~dB}$ representing matrix cracking and the distribution pattern is a characteristic feature for the given specimen. The skew of the distribution indicates the relative strength of the specimen.

iii) The cumulative amplitude distribution gives an insight in to the presence of two dominant failure mechanisms with appearance of two distinct slopes. Theslope of the representing the matrix cracking ranges from 0.9 to 1.3 and that of fiber breakage ranges from 0.45 to 0.7 .The point of inflection in the cumulative amplitude plot at 85 to $90 \mathrm{~dB}$ indicatesinitiation of fiber breakage.

iv) The cumulative signal strength plot indicates the initiation of damage in the specimensat about $70 \%$ to $80 \%$ of the load with a steep change in slope.The onset of historic index exceeding 6 at the same locationalso 
indicates damage initiation. The fiber failure mechanism is represented by high energy and longer duration hits.

\section{Acknowledgements}

The authors are thankful to The Director, Advanced Systems Laboratory, Hyderabad for supporting the research work.

\section{References}

[1]. American Society for Nondestructive Testing, 2005, "Nondestructive Testing Handbook-Third Edition, Volume 6, Acoustic Emission Testing,"Ronnie K. Miller, Eric v.K. Hill, Patrick O. Moore, American Society for NondestructiveTesting,Ohio.

[2]. Chen, F., Hiltner, A., and Baer, E., 1992, "Damage and Failure Mechanism of Continuous Glass Fiber Reinforced PolyphenyleneSulfide," Journal of Composite Materials, Vol. 26, No. 15, pp. 2289-2306.

[3]. Suzuki, H., et al., 2000, "Integrity Evaluation of Glass-Fiber Composites with Varied Fiber/Matrix Interfacial Strength Using AE," NDT\&E International, Vol. 33, pp. 173-180.

[4]. M. Ciordano, ACalabro, C.Esposito, A.Damore and L.Nicolais, "An AE Characterization of the failure modes in Polymer Composite materials", Composite science and Technology 1998.Vol 58(12) PP 1923

[5]. ASTM Standard 3039, "Standard Test Method for Tensile Properties of Polymer Matrix Composite Materials", American Society for Testing Materials, ASTM International, West Conshohocken, PA, 2003

[6]. J.L.Walker II, "Ultimate Strength Prediction of ASTM D 3039 Tensile Specimens from Acoustic Emission Amplitude Data", AIAA 92-0258.

[7]. Kim, R. Y. and S R. Som. "Experimental and Analytical Studies on the Onset of Delamination in Laminated Composites," J Composite Materials, 18:70-80 (January 1984)

[8]. Herakovich, C. T "On the Relationship Between Engineering Properties and Delamination of Composite Materials," J. Composite M,aterials 15:336-348 (July 1981).

[9]. N. Ativitavas,"Acoustic emission signature analysis of failure mechanisms in fiber-reinforced plastic structures," PhD thesis United States -- Texas, The University of Texas at Austin, 2002. 